\title{
Analysis on the Impact of New Media During COVID-19 Epidemic
}

\begin{abstract}
Xiangyi Li
St. Joseph High School, Trumbull, Connecticut, 06611

*Corresponding author. Email:1225659630@qq.com

ABSTRACT

During the COVID-19, the new media played an important role in conveying information, guiding public opinion and reassuring people. New medias have rallied people's minds and encouraged the public not to give up in the face of the epidemic. In addition, the new media was being developed rapidly and used efficiently. Under the widespread use of new media, public with the lack of professional media literacy is also given the power of publishing information. New media can improve the timeliness and diversity of epidemic reporting, protect the citizens' right to know, and play a useful role in media supervision. Furthermore, due to the diversified characteristics of new media communication subjects, it also leads to the epidemic situation Internet rumors have increased and causes panic among the public. New media have both positive and negative effects in the process of fighting the epidemic. This article analyzes the positive and negative effects of the epidemic on new media, and finds out how to use new media correctly, so as to maximize the use of new media.
\end{abstract}

Keywords: New media, COVID-19 epidemic, positive and negative

\section{INTRODUCTION}

The sudden outbreak of COVID-19 in China has made people nervous. Meanwhile, the coronavirus has changed people's habits and frequencies of using new media. To protect themselves, people began to take additional precautions, staying indoors and keeping social distances. Since then, people have been spending most of their time on the new media such as Weibo, WeChat, TikTok, etc. These have gradually surpassed traditional media in their influence in the epidemic due to their fast transmission speed, wide information dissemination coverage and strong interactivity. The data of increasing usage of the new media during the coronavirus outbreak period shows that the Wechat was being used to $50.8 \%$, Traditional media websites achieved $48.8 \%$, Weibo had $32.6 \%$ on using it[1]. During the epidemic, the content production and interaction on TikTok and Weibo have increased significantly. For example, people at home begin to watch videos on these apps to learn how to cook food and share their experiences with each other online, creating a strong atmosphere of sharing and interaction. As the eMarketer forecasting analyst Brain Lau mentioned, "Quarantines have pushed adults in China to spend even more time on internet-connected activities and have accelerated the shift toward digital."'[2] Qing Deng believes that the location of citizens and distance from a disaster influence the social media usage patterns[3]. Combining situation of epidemic, public hospitals can do a good job in epidemic prevention and control propaganda from social media cooperation[4]. In this epidemic, the role of new media is not only to provide entertainment and convenience for people, but more importantly to convey information, guide public opinion and reassure people. The development of new media is so rapid that ordinary people, lacking professional media literacy, are given the right of information publishers, guaranteeing citizens' right to know, and playing a good role in media supervision in the fight against the epidemic. But on the other hand, due to the diversification of the dissemination of new media, leading to the increase of rumors, causing panic among the masses. Therefore, the impact of new media on the epidemic is both positive and negative.

\section{POSITIVE EFFECTS}

With the rapid development of new media, human society has been unwittingly brought to a new media environment. There are many positive effects of new media, especially from four aspects. Helping solve the national crisis and reporting misconduct, and acting as the media supervision. Delivering fast and accurate information play an early warning role to the public. It guides public's opinions and setting up a correct guidance of personal values. Providing a new convenience way to help people remais in their normal daily life, even though the virus is affecting them.

\subsection{Helping Solve National Crisis And Reporting Misconduct}

The Covid-19 epidemic is demonstrating the power of new media to swiftly and creatively respond to the national crisis. For example, "Within a month, digital ecosystems enabled China to roll out a contracting system that by 
mid-April had tracked the health and movements of nearly 450 million individuals through phone apps and identified 160,000 cases of close contact with infected individuals". The high speed of new media communication plays a unique role in the process of media public opinion supervision. For instance, after the outbreak of Covid-19, masks, medicines, foods and other related items were snapped up by the public. Some sellers took the advantage of the situation to raise prices.

People recorded and published those events on new media, such as TikTok and Weibo, which caused the attention of the relevant departments. Then the government issued new policies to curb the wave of price increases. And also, if there was someone holding a party or some events with a lot of people, all of these activities that gather people together have been reported with the new media, so that the government could strengthen the regulating. No matter who you are, everyone can use new media to share, record or report things that are happening around, thus everyone can see and keep sharing.

All the problems mentioned, the disclosure on the new media platform played an important role in the supervision of public opinion for the first time. During the epidemic, new media has become a 'bridge' to communicate efficiently between the public and the government.

\subsection{Delivering Fast and Accurate Information}

Due to the non stagnation of the transmission of new media, it acted a better role in the reporting of the epidemic than traditional media. When the Covid-19 has first appeared, new media has reported immediately. Soon afterwards, doctors and experts started to teach the public the basic knowledge of Covid-19 and how to prevent themselves from the epidemic through the new media that staying at home, drinking and eating more Vitamin supplements, wearing masks all the time, etc. During this crisis, the new media passed the knowledge of current disease statistics and its prevention to the general population at a rate equivalent to or better than the spreading epidemic. New media has played a significant role in againsting and preventing the Covid-19 during the epidemic. In the late stage of the epidemic, new media quickly brought the news and data for the first time. The public knew that the epidemic was improving gradually with continuous efforts, and the number of infections was decreasing, which let people see the dawn and hope.

The fast spread of new media makes people have a sense of prevention immediately after the outbreak of the epidemic. As most of the people have heard, before the public knew about the epidemic, a doctor has released the initial information of the epidemic through Weibo, WeChat and other new media, and this doctor became a 'whistleblower' in the eyes of the public. Thus, delivering fast, accurate and reliable information addressing critical problems of infection control is, therefore, of key importance. New media played a better role in early warning and surveillance, so as to attract the attention of relevant departments and make them take effective measures to nip the potential crisis in the bud and avoid the escalation of the crisis through supervision by public opinion.

\subsection{Guiding Public's Opinions}

The new media supported in guiding the public's opinions and establishing a correct guidance of personal values. After the outbreak of the epidemic, the general public might have a certain amount of panic and negative behavior. At this time, expect transmitting information, new media also need to conduct public opinion guidance, in order to help the public understand and analyze the events. "Opinion leaders" such as entertainers, celebrities, "Big Vs" on Weibo and the accounts with many followers had released information through new media to support doctors and volunteers. But traditional media because of its "official" attribute, slightly rigid in public opinion guide, so the advantage of new media to stand out. Exhorted people to pay

attention to the information such as personal protection, played a good public opinion guide, also set up the correct values orientation.

\subsection{Providing A New Convenience Lifestyle}

Although propaganda films, medical programs and documentaries can spread epidemic knowledge and anti-epidemic information directly, entertainment channels are more likely to attract the attention and resonance of young people. Therefore, new social media platforms such as Tiktok played an important role in combating the spread of epidemic awareness in this epidemic. New media not only plays an important role in conveying information, guiding public opinion and soothing people's hearts, but also provides people with a more convenient way of life in a new way under the special period. Since most people in China are locked down at home, it is hard for them to go out. The shopping app Meituan has launched a new operation to promote the online and offline integration of fresh retail, which provides a convenient way for people to shop.

More and more people started buying fresh fruits and vegetables through this app under the epidemic, even the middle-aged and elderly people who also began to use it[5]. Also, with the lock down policy, people began to learn how to cook and share their cooking skills and results on the apps, such as TikTok, Weibo, Little Red Book, etc. It has suddenly become a new activity that people can enjoy themselves when they are inside the house. Some even became web celebrities with plenty of followers for sharing their skills, hobbies and life with the new media under the epidemic, especially by using TikTok. The new media is fair to give everyone a chance to make themselves valuable. In addition, online teaching and online interaction enabled students who were unable to enter the campus to learn without being delayed by the epidemic. 
All the schools started to provide online courses. Even though the epidemic has affected people's normal life, the new media applied a new way to help people try not to change their lives. Moreover, the active participation of new media can also slow down the pressure of the public. New media, including WeChat, weibo and short video APP, have set up comment areas, which is to set up a public opinion space for the public to vent some of their dissatisfaction with the society gathered during the crisis to alleviate or eliminate hostility or dissatisfaction. In the meantime, new media also plays an important role as a social "pressure relief", decreasing some intense social emotions and maintaining the normal life and relations of the social groups.

\section{NEGATIVE EFFECTS}

But along with these advantages, the negative effects of new media also appear. Through new media, a large number of fake news was quickly published and forwarded without any verification or professional certification. Many privately run new media are unprofessional and unverifiable, but have pandered to the masses by publishing content of poor quality, exaggeration and panic. People demonize and belittle the epidemic area, degrade the reputation of the people in the epidemic area. People over vent their emotions and exaggerate the atmosphere of panic. This has not only caused a negative impact on social management, but also caused great disturbance to researchers.

\subsection{Fake News Are Being Published And Forwarded Rapidly}

During the epidemic, some false reports appeared frequently, especially on medical knowledge. People in panic began to believe all kinds of reports blindly even without thinking for emotional reasons. During the epidemic, people pay more attention to life, food safety and the health and medical knowledge. Through the new media platform, some people act as medical experts to mislead the media and public. For example, the typical representative of rumors "panic purchasing Shuang Huang Lian " event. A Number of people published some posts about Shuang Huang Lian which can be a useful way of medical treatment to people who are carrying the virus and preventing people from infecting the virus. This misled the public to buy Shuang Huang Lian, which has made the drugstore and hospital lack Shuang Huang Lian for a long period of time. With the advantages of new media, some people started to create fake news because they wanted to get more attention and followers.

On TikTok, some accounts post about Covid-19 becoming stronger and more and more people might infect. Due to people's selfishness, these fake news will bring a lot of unnecessary panic, which must be stopped in time. The truth rumors mainly appeared in the early stage of the outbreak. The public had limited understanding of the epidemic and were eager to get information on why the outbreak occurred, the percentage of the death rate and whether it could be cured or not. Some new media accounts are grasping the thoughts of the public, throwing out alarmist remarks and attracting attention.

\subsection{Demonized And Belittled People from Epidemic Area}

Many rumors demonized and belittled the people who are living in the epidemic area. For example, the outbreak in China started in Wuhan, so people began to deliberately avoid people, food and vehicles from Wuhan. Some people make fun of people who are from Wuhan via the new media. As we all know that the cause of the virus is from a small number of people eating wild animals. But rumors started to blame on all the Wuhan citizens.

This kind of behavior makes Wuhan people suffer a lot of pressure and discrimination. The new media is a platform for freedom of speech, where people can say what they want to say without much limitations, and others can see their speeches and thoughts at any time. For those rumors, they might just type some words behind the screen to express their ideas and feelings, but they hurt others unintentionally or intentionally. The advantages of new media sometimes can become its shortcomings. For example, release of news without delay, when these bad comments are published, it is not good news for some people. When people don't talk and express their ideas in person, they might now care much about other people's feelings.

\subsection{Over-vented Emotions And Exaggerated Atmosphere of Panic}

New media has the characteristics of fast transmission and concise content. It allows people living in a fast-paced life to unconsciously speed up and refresh themselves to obtain more information and opinions. So that people can easily show their panic and anonymously express their opinions without too much thinking. A lot of panic and complaining posts from the public could be found. It is hard for us to ignore those opinions. From the psychological aspect to view this situation, it can be concluded that a person with a bad mood will affect others around[6]. This can also apply to the new media world as people are all connected by the media nowadays. When people focus too much on the fear of death and disease, it is easy to cause panic among the public. But because people are stressed and depressed during the epidemic, the Internet is the only way for them to communicate and vent. Without considering others, vent anything that they want to say on the new media platform. All people who see those negative comments will be affected. This kind of behavior is irresponsible and selfish for themselves and also others. 


\section{CONCLUSION}

The outbreak of COVID-19 has promoted the rapid development of new media, allowing more people to be exposed to and learn about new media during this period. With the development of new media, it is necessary to ensure that the information disseminated is positive, true, accurate and harmless. Truly valuable and meaningful information is not the bottomless publishing of bad content in order to achieve the goal of increasing public exposure, but the nature of new media as a communication tool, the possibilities it creates and the changes it brings to society. Second, one of the characteristics of new media is that its content is"fragmented". The result is that public knowledge of the epidemic is fragmented, not complete. Therefore, in order for the public to rise from perceptual knowledge to rational knowledge of events, people engaged in new media not only need to strengthen in-depth analysis and professional interpretation of events, but also constantly enrich the level of reporting and make comprehensive analysis of events. The content released by new media is short, substantial, and reliability is the biggest goal of new media practitioners. In addition, new media should become a way for people to relax and entertain themselves, instead of letting online media become the fuse that intensifies social conflicts. While enjoying the benefits of new media, it is also necessary to maintain a good order of network communication. If used wisely and prudently, new media serves as a powerful tool for changing people's behavior and to promote the well-being of individual and public health.

\section{ACKNOWLEDGMENT}

It is a great honor for me to participate in the course taught by Professor Wegenstein, which is a great help to me. Through this class, I have deepened my understanding of new media and learned a lot about the history and theories of new media. This has played a great role in my future choice of college major. This experience of learning new media courses made me unforgettable, and it was a very precious time for me. Thanks again for the professor's kind instruction.

\section{REFERENCES}

[1] China: Coronavirus Impacted Increase in Digital Media Usage by Type 2020. Statista, 26 May 2020, www.statista.com/statistics/1108326/china-digital-medi a-usage-increase-in- coronavirus-covid19 -outbreakperiod-by- type/
[2] Time Spent with Media in China Grows amid COVID-19 Pandemic. InsiderIntelligence, 24 April.2020, www.emarketer.com/newsroom/index.php/time-spentwith-medi-in-china-grows-amid -covid-1-pandemic/.

[3] Qing Deng, Yi Liu, Xiaodong Liu, et al. Social Media Usage During Disasters: Exploring the Impact of Location and Distance on Online Engagement. 2020, 14(2):183-191.

[4] Weiyi Yao. Research on the New Media Communication Strategy of Public Hospitals in the Prevention and Control of New Coronary Pneumonia Epidemic[D]. Beijing Institute of Graphic Communication, 2020.

[5] Chan, Ted, et al. "How Chinese Digital Ecosystems Battled COVID-19.” BCG Global, 10 Aug. 2020,w ww.bcg.com/publications/2020/how-chinese-digital-eco systems-battled-covid-19

[6] "How Emotions Affect Other People." Emotion Researcher, 21June. 2019, https://emotionresearcher.com/how-emotions-affect-oth er-people/ 